\title{
Effect of Slow Stroke Back Massage on Depression and Anxiety among Post-Stroke Geriatric Patients
}

\author{
Saer Mourith Tannous, Demonstrator \\ Gerontological Nursing, Faculty of Nursing, Tishreen University, Syria
}

\author{
Nagwa Abd El-Fattah Ibrahim, Professor \\ Gerontological Nursing, Faculty of Nursing, Alexandria University
}

Marwa Abd El-Gawad Ahmed Mousa, Lecturer

Psychiatric Nursing and Mental Health, Faculty of Nursing, Alexandria University

\begin{abstract}
Post-stroke depression and anxiety are the most common emotional changes after a stroke. They can impair patient's functional recovery, rehabilitation and community reintegration. It was postulated that applying skillful nursing interventions, such as the Slow Stroke Back Massage (SSBM), can improve patient's levels of depression and anxiety. Objective: This study aimed to determine the effect of slow stroke back massage on depression and anxiety among post-stroke geriatric patients. Setting: The study was conducted at the neuropsychiatry inpatient unit in El-Hadara University Hospital for Orthopaedics and Neuropsychiatry, Alexandria, Egypt. Subjects: The study subjects comprised 50 post-stroke geriatric male patients. Tools: Four tools were used to collect data; the Mini Mental State Examination (MMSE) Scale, Geriatric Patients' Socio-Demographic and Clinical Data Structured Interview Schedule, Geriatric Depression Scale-Short Form (GDS-SF) and Beck Anxiety Inventory (BAI). Results: The percentages of subjects who had moderate and severe levels of depression significantly decreased after applying the SSBM. The percentage of those who had moderate level of anxiety significantly decreased, while no patient was found to have severe anxiety after receiving the SSBM. Conclusion: The SSBM is a clinically effective nursing intervention that can significantly reduce levels of depression and anxiety among post-stroke geriatric patients. Recommendations: Include the SSBM as an integral part in the gerontological and psychiatric nursing courses, and develop training programs for both nurses and caregivers of post-stroke geriatric patients about the SSBM.
\end{abstract}

Keywords: Post-stroke depression, Post-stroke anxiety, Geriatric patients, Slow Stroke Back Massage (SSBM).

\section{Introduction}

Stroke is one of the most leading causes of disability worldwide. The World Health Organization (WHO) has defined it as a neurological deficit of cerebro-vascular cause that persists beyond 24 hours or is interrupted by death within 24 hours. Stroke is caused by either a blockage or rupture of a blood vessel to the brain which results in tissue death and cause neurological impairments $^{(1)}$.
There is a number of common ways in which stroke can affect a person. Its survivors can experience physical disability and difficulties in processing language, reading, articulating, and/or swallowing. In addition, successful return to physical levels after stroke is particularly low ${ }^{(2)}$. Post-stroke complications can be classified into further neurologic-related complications, medical complications, post-stroke difficulties and handicaps, such as movement disabilities, contractures, communication problems, and 
psychiatric problems such as depression and $\operatorname{anxiety}^{(3,4)}$.

Researches indicate that living with stroke is one of the most stressful life events that may trigger emotional changes ${ }^{(5,6)}$. These emotional changes are common and occur in at least one third of patients in the first year after the onset of a stroke ${ }^{(2,7)}$. The most common changes in emotions are poststroke depression (PSD) and anxiety $(\mathrm{PSA})^{(4,5,8)}$.

Broomfield et al. (2014) suggested that symptoms of depression and anxiety are common and their rates are high following stroke events ${ }^{(9)}$. Clinical studies estimated that PSD occurs in approximately one third of the patients, whereas the incidence rate of PSA is between $18 \%$ and $28 \%{ }^{(10-12)}$. It was also reported that the major occurrence of PSA comes with PSD ${ }^{(13)}$.

The possible risk factors of developing both PSD and PSA include poststroke physical handicap and limitations in activity of daily living, advanced age, pain, cognitive impairments, lack of social support and social isolation ${ }^{(7,14)}$. Moreover, stroke is associated with significant psychosocial difficulties which have an impact on the development of depression and anxiety. These include grief at loss of mobility function and flexibility, independence, work, and income. Added to these that geriatric patients already have different physical and psychosocial changes related to advancing age, e.g., chronic diseases and loss of partner. Such difficulties and losses result in reduced selfesteem and confidence and lowered feelings of self-worth ${ }^{(6,8,10)}$. Unfortunately, geriatric patients who have had a stroke are also susceptible to many complications. Cardiovascular complications, pneumonias, venous thromboembolism, fever, pain, incontinence, depression and anxiety are particularly common after a stroke ${ }^{(4,10)}$.

Post-stroke depression and anxiety are still unresolved issues that influence the long-term health outcomes of patients with stroke. They can impair patient's functional recovery, rehabilitation and community reintegration $^{(15-17)}$. More specifically, untreated PSD and PSA can make it hard for patients to manage their stroke treatment effectively. They can find it difficult to concentrate, stay motivated, keep appointments and stick to treatment plans, including medications ${ }^{(6)}$. Prolonged inpatient hospital stay, greater disability with activities of daily living, poor cognitive functioning, severe physical impairment, reduced physical and social activities, and higher health care costs are among the poor functional and psychosocial outcomes of PSD and PSA ${ }^{(7,10,14,16)}$.

Although PSD and PSA are relatively common and usually require specific medical and nursing interventions, they are often unrecognized and probably most geriatric patients do not receive effective management or adequate treatment ${ }^{(17,18)}$. Managing these post-stroke psychological problems through applying both psychopharmacologic and nonpharmacological interventions can improve patient's wellbeing and recovery. In this respect, it was argued that nonpharmacological complementary therapies may not only help with recovery and rehabilitation, but can also help prevent the recurrence of depression or anxiety ${ }^{(7)}$.

Massage now is usually considered an alternative or complementary therapy rather than a conventional nursing intervention $^{(19,20)}$. Massage therapy is the scientific manipulation of the soft tissues of the body for the purpose of normalizing those tissues. It consists of manual techniques that include applying fixed or movable pressure, holding, and/or causing movement of or to the body ${ }^{(21)}$. This therapy has a number of documented clinical benefits. It is known to stimulate blood circulation and lymphatic drainage, and enhance tissue healing. Thus, it provides a number of advantages which include reducing muscle tension, stiffness and flaccidity, relieving stress, promoting 
mental and physical relaxation, and creating a feeling of well-being ${ }^{(20-22)}$.

Nurses have a long history using back massage to provide comfort, relaxation, induce sleep, and reduce anxiety in their patients. Under the auspices of complementary and alternative therapies, and beside all clinical advantages of massage, therapeutic back massage is recommended for post-stroke patients to stimulate and restore normal functioning of nerves ${ }^{(19)}$.

The slow stroke back massage (SSBM) is a non-pharmacological intervention that has been used since the time of Florence Nightingale to relieve physiological and psychological stress and promote restorative sleep. It was described as a specific nursing protocol since the mid1960s. The SSBM consists of slow, gentle, rhythmic stroking using two hands simultaneously. The hands move at a rate of 60 strokes a minute over a 2 -inch-wide area (approximately $5 \mathrm{~cm}$ ) on both sides of spinous processes from the crown of the head to the sacral area. The entire massage lasts for three to ten minutes ${ }^{(23,24)}$.

It was reported that this type of massage is simple, easy to be administered, non-threatening, non-invasive and costeffective. It takes only a brief time, and requires minimal supplies of massage oil or lotion ${ }^{(23,25-27)}$. Research evidences also confirmed the fruitful effects of SSBM on physiological and psychological relaxation in older people ${ }^{(20,24,28)}$.

Literature supports that professional nurses can be in authority with complementary therapies ${ }^{(20)}$. They are responsible for implementing comprehensive nursing interventions in order to improve patients' psychosocial condition after stroke and minimize the limitations that impair their full recovery ${ }^{(25)}$. It was postulated that applying skillful and creative nursing interventions, such as SSBM, for post-stroke geriatric patients can assist them in optimizing independence and overall functional ability, which consequently improve their psychosocial status $^{(25,28)}$.

Although previous studies reported the positive effects of SSBM in reducing pain, blood pressure, heart rate, depression and anxiety, and improving relaxation and sleep hours in older adults ${ }^{(20-25,27,28)}$, little is known about the effect of this nonpharmacologic intervention on both PSD and PSA on Egyptian subjects.

\section{Aim of the Study}

The present study aimed to determine the effect of slow stroke back massage on depression and anxiety among post-stroke geriatric patients.

\section{Research Hypothesis:}

Post-stroke geriatric patients who receive slow stroke back massage exhibit lower levels of depression and anxiety than before receiving it.

\section{Materials and Method}

\section{Materials}

Design: This study followed a quasiexperimental design.

Setting: The study was conducted at the neuropsychiatry inpatient unit in El-Hadara University Hospital for Orthopaedics and Neuropsychiatry, Alexandria, Egypt. The hospital serves three governorates, namely; Alexandria, EL-Behera and Matrouh.

The unit has four rooms with a total capacity of forty four beds; two rooms for males which include 19 beds, and two rooms for females which include 25 beds. This unit provides free treatment services for all patients suffering from psychiatric and neurological disorders, from all age groups.

Subjects: The Epi info 7 program revealed a sample size of 33 patients. To ensure more generalization of the study findings, the 
researchers decided to recruit a convenient sample of 50 post-stroke geriatric male patients who are 60 years and above, have no severe cognitive impairment, free from pressure ulcers, not critically ill, and able to communicate in a coherent and relevant manner.

Tools: Four tools were used to collect the necessary data:

\section{Tool I: Mini Mental State Examination (MMSE) Scale}

Folstein et al. (1975) developed this 30point standardized scale to detect the severity and progression of cognitive impairment ${ }^{(29)}$. It assesses the following areas of cognitive functioning: orientation, registration, attention and calculation, recalling, as well as language and visual construction.

The MMSE scale provides a total score ranging from 0 to 30 . A score from 0 to 17 indicates severe cognitive impairment, a score from 18 to 23 indicates mild cognitive impairment, and a score of 24 or more is indicative of normal cognitive functioning.

The scale has been validated and extensively used in both clinical practice and research of older adults' cognitive functioning $^{(30,31)}$. In Egypt, the MMSE scale was tested for validity and reliability after translating it into Arabic language by ElHusseini (2008). It was valid and reliable $(\text { Cronbach's alpha }=0.82)^{(32)}$. In the present study, this scale was used to exclude poststroke geriatric patients with severe cognitive impairment.

Tool II: Geriatric Patients' SocioDemographic, Social Activities and Clinical Data Structured Interview Schedule

This interview schedule was developed by the researchers to elicit data related to general socio-demographic and clinical characteristics of the study subjects. It includes two parts: $\checkmark$ Part I: Geriatric Patient's Sociodemographic Characteristics, Social Activities and Habits: This part covers socio-demographic characteristics of the study subjects such as age, marital status, occupation before retirement, recreational activities, and smoking history.

$\checkmark$ Part II: Geriatric Patient's Clinical Data: This part includes patient's health status and clinical characteristics related to the presence of chronic diseases other than stroke, currently prescribed medications, stroke-related data (type, onset, affected side, duration of being diagnosed with stroke, type of functional decline, and presence of stroke-related medical complications), and emotional status as reported by the patient.

Tool III: Geriatric Depression ScaleShort Form (GDS-SF)

This scale was developed by Sheikh and Yesavage (1986) ${ }^{(33)}$ as a short form derived from the Geriatric Depression Scale-Long Form (GDS-LF) ${ }^{(34)}$.

It consists of a subset of 15 questions, derived from the GDS-LF, to which geriatric patients respond either by "Yes" or "No" in reference to how they felt over the past week.

Total score of the GDS-SF ranges between 0 and 15. A score from 0 to 4 indicates no depression, a score from 5 to 8 indicates mild depression, a score from 9 to 11 indicates moderate depression, and a score from 12 to 15 indicates severe depression.

The GDS-SF was translated into Arabic language by El-Husseini (2013) and proved to be valid and reliable (Cronbach's alpha $=0.70)^{(35)}$.

\section{Tool IV: Beck Anxiety Inventory (BAI)}

The BAI was developed and validated by Beck et al. (1988) to measure the severity of an individual's anxiety ${ }^{(36)}$. It consists of 21 
items assessing the subject's feeling in the last week, and expressed as common symptoms of anxiety (e.g., numbness and tingling, sweating not due to heat, and fear of the worst happening).

The subject is asked to rate how much each symptom has bothered him in the past week. The symptoms are rated on a fourpoint scale, ranging from "not at all bothered" (0) to "severely bothered" (3).

The BAI has a maximum score of 63 , where anxiety levels are defined as minimal (0-7), mild (8-15), moderate (16-25) and severe (26 and above).

This inventory was translated into Arabic language by Laila (2012) and reported to be valid and reliable (Cronbach's alpha $=0.79)^{(37)}$.

\section{Method}

- Official permissions to conduct the study were obtained from the responsible authorities of El-Hadara University Hospital for Orthopaedics and Neuropsychiatry.

- Tool II (Geriatric Patients' SocioDemographic, Social Activities and Clinical Data Structured Interview Schedule) was developed by the researchers based on relevant literature.

- A pilot study was carried out on six post-stroke geriatric inpatients in order to ascertain the clarity and applicability of the study tools, and to identify obstacles that may be faced during data collection. Subjects who included in the pilot study were excluded from the study sample. Results of this pilot study revealed that tools were clear and applicable.

- A schedule for data collection was designed by the researcher. According to the designed schedule he used to be available at 9.00 am in the neuropsychiatry inpatient unit daily from Saturday through Thursday.

- The actual data collection started by reviewing all patients' medical charts using tool II to identify poststroke inpatients aged 60 years and above.

- Each recruited patient was interviewed individually in the neuropsychiatry inpatient unit and invited to participate in the study. After that tool I (MMSE Scale) was applied to include subjects who fulfill the inclusion criteria (having no severe cognitive impairment).

- After ensuring that the patient meets the inclusion criteria, sociodemographic, social activities and clinical characteristics of the patients were more elicited using tool II (Geriatric Patients' SocioDemographic, Social Activities and Clinical Data Structured Interview Schedule).

- Assessment of patient's post-stroke depression and post-stroke anxiety was done using tools III and IV respectively.

- The study intervention (SSBM) was carried out by the researcher through the following steps ${ }^{(19,20,24-28)}$ :

a) The researcher used to perform the SSBM far from the hospital routine procedures (between 10:00 am and 1:30 pm and between 5:00 pm and 8:00 pm) after coordination with the nursing and medical personnel.

b) The researcher was able to complete the study intervention for one to three patients per day.

c) Preparing the environment for the application of the intervention was started by ensuring that the patient's room is quiet and warm. 
d) Each patient was assisted to be in the most comfortable position where full back is accessible for the researcher. The SSBM was performed while the patient was in either prone or sitting position according to the patient's preference and health condition.

e) Blood pressure and pulse were measured and recorded 5 minutes before applying the SSBM to ensure that they are within the normal range.

f) The researcher used to warm his hands using warm water.

g) To avoid skin injury, the researcher used the Paraffin oil as a lubricant for patient's back and neck skin. Paraffin oil was reported as free from essential oils that may interfere with the study results ${ }^{(19)}$.

h) The top of the patient's shoulders were firmly grasped by the researcher with both hands and thumbs of each hand were placed just below the base of the skull, and tiny circular movements on the upper neck were made.

i) One palm of the researcher's hand was placed at the base of the patient's skull and smooth strokes were made all the way down the patient's spine to his waist. The second hand follows the first at the base of the skull and strokes down the spine as the first hand returns to the base of the skull.

j) The researcher's hands were placed on either side of the patient's neck under his ears and stroke down and over the patient's collarbones with thumbs just over the shoulder blades. This step was repeated five or six times.

k) The thumb of each hand was placed beside the spine, beginning with the shoulders, and the thumbs were moved down the spine to the waist. This step was repeated five or six times.

1) Finally, palms of the researcher's hands were placed on each side of the patient's neck and continuous, long sweeping strokes were made down the neck, across each shoulder, and down the back near the spine. The entire pattern was repeated five or six times.

m)Blood pressure and pulse were reassessed and recorded 5 minutes after applying the SSBM.

- The researcher used to repeat the procedure for five consecutive days (one session per day), for a duration of 6-8 minutes per session.

- By the end of the final session of SSBM, patient's levels of PSD and PSA were reassessed using tools III and IV respectively to compare the results with the base line data.

- Data collection started from the beginning of September 2014 until the end of March 2015.

\section{Ethical considerations:}

Throughout the study phases:

- A signed written informed consent was obtained from the study subjects after appropriate explanation of the study aim.

- Anonymity and privacy of the subjects and confidentiality of the collected data were always respected and assured.

- The right to refuse to participate or to withdraw from the study was emphasized.

\section{Statistical Analysis}

- Collected data were coded and transferred into specially designed 
formats suitable for computer feeding.

- The following statistical measures were used:

A. Frequency, percentage, minimum, maximum, median, arithmetic mean, and standard deviation were used for descriptive presentations.

B. Statistical tests included Exact Mc-Nemar test, independent Student t-test, Wilcoxon test, Ftest (One-Way Analysis of Variance: ANOVA), and mean percent change.

- Levels of significance for this study were $\mathrm{p}$-values equal to or less than 0.05 and 0.01 .

\section{Results}

Table (1) describes the sociodemographic characteristics of the studied subjects. Their age ranged between 60 and 89 years, with a mean age of $65.64 \pm 6.19$ years. Subjects who were married constituted $80.0 \%$, while $18.0 \%$ of them were widowers and one patient $(2.0 \%)$ was divorced.

Regarding the educational level, it was found that more than one third $(38 \%)$ of the studied subjects were illiterate, while those who read and write constituted $20 \%$. The rest of the subjects received basic education (primary and preparatory), and secondary and intermediate education (diploma) $(16.0 \%, 18.0 \%$ and $8.0 \%$ respectively).

As for the occupation before retirement, $62.0 \%$ of subjects were manual workers, while employees and those who had private jobs (e.g., traders and businessmen) constituted $24.0 \%$ and $14.0 \%$ respectively.

The table also shows that $90 \%$ of the subjects reported that they are living in their own homes either with their families or are living alone $(8 \%)$ and one patient $(2.0 \%)$ stated that he is living with a relative in his home.

Subjects who had previous recreational activities and hobbies constituted $96.0 \%$ of the studied sample. These activities included going to café and meeting friends $(68.8 \%)$, playing cards, chess or dominoes $(22.9 \%)$, and reading $(8.3 \%)$.

As regards smoking history, subjects who were ex-smokers and current smokers constituted $70.0 \%$ and $24.0 \%$ respectively. The duration of their smoking ranged between 10 and 50 years, with a mean of $37.81 \pm 9.45$ years. These ex-smokers and current smokers reported that they used to smoke cigarettes and shisha $(83.0 \%$ and $17.0 \%$ respectively).

Table (2) presents health status and clinical characteristics of the studied subjects. It was found that more than one half $(54.0 \%)$ of subjects had normal cognitive functioning, whereas $46.0 \%$ had mild cognitive impairment as measured by the MMSE Scale. The results also indicated that chronic diseases other than stroke were present in the majority of the studied subjects $(98.0 \%)$. More than three quarters of these patients $(76.0 \%)$ suffered from hypertension, while $48.0 \%, 38.0 \%$ and $30.0 \%$ of patients had hyperlipidemia, diabetes and chest pain respectively.

Concerning currently prescribed medications, it was noticed that phosphodisterase inhibitors, heparinzation and antiplatelet regression, anti-hypertensive and lipids lowering drugs, and nutritional supplements were the most frequently prescribed medications $(96.0 \%, 88.0 \%$, $82.0 \%, 82.0 \%$ and $72.0 \%$ respectively), whereas insulin, bronchiodilators, and anticonvulsive agents were the least frequently prescribed medications as recorded in the patient's chart $(10.0 \%, 2.0 \%$ and $2.0 \%$ respectively).

Regarding emotional status in the hospital as reported by patients, most of them $(82.0 \%)$ reported that they feel sad and uncomfortable, more than two thirds of 
them $(68.0 \%)$ felt anxious, and more than a half of the patients $(58.0 \%)$ felt helpless.

The table also shows stroke-related data. It was observed that $60.0 \%$ of the subjects had ischemic thrombotic stroke. The rest had ischemic lacunar stroke, ischemic embolic stroke and intra-cerebral hemorrhage $(20.0 \%, 18.0 \%$ and $2.0 \%$ respectively). It was also noted that $88.0 \%$ of the subjects had a stroke for the first time and $12.0 \%$ had recurrent strokes. The affected side in $58.0 \%$ of the subjects was the right one, while the left side was affected in $42.0 \%$ of the studied subjects. The duration of being diagnosed with stroke for all subjects ranged between 3 and 21 days $(64.0 \%$ of them had a duration of 3 to less than 7 days), with a mean of $7.62 \pm 3.6$ days.

Concerning the functional decline as recorded in patient's chart, most of the subjects $(88.0 \%)$ had hemiparesis and about two thirds of them (66.0\%) had mood changes, followed by sensory loss, communication problems, dysphagia and hemiplagia $(62.0 \%, 60.0 \%, 16.0 \%$ and $12.0 \%$ respectively).

The results revealed that stroke-related medical complications were found among more than three quarters of the studied subjects $(78.0 \%)$. The most frequently noted complications were constipation (56.0\%) and urinary incontinence $(30.8 \%)$.

Table (3) portrays the study subjects' levels and mean scores of PSD before and after the intervention and its mean percent change after applying SSBM. One can notice that percentages of subjects who had moderate and severe levels of depression decreased from $16.0 \%$ and $18.0 \%$ respectively before the SSBM to $4.0 \%$ and $8.0 \%$ respectively after applying it. On the other hand, percentages of subjects who had no depression and mild level of depression were $42.0 \%$ and $24.0 \%$ respectively before applying SSBM. These percentages increased to $60.0 \%$ and $28.0 \%$ respectively after receiving it.
The difference between levels of depression among the studied subjects before and after the SSBM was statistically significant $(\mathrm{p}=0.048)$. The table also shows that the mean score of PSD significantly decreased from $6.3 \pm 4.3$ before the SSBM to $4.4 \pm 3.3$ after applying it. This mean score significantly improved by a percentage of $26.41 \pm 25.33$ after receiving SSBM $(\mathrm{p}=0.025)$.

Table (4) presents study subjects' levels and mean scores of PSA before and after the intervention and its mean percent change after applying SSBM. It was observed that before the study intervention subjects who had minimal, mild, moderate and severe levels of anxiety constituted $40.0 \%, 24.0 \%$, $22.0 \% 14.0 \%$ respectively. After receiving the SSBM, the percentage of those who had moderate level of anxiety decreased to $14.0 \%$, while there were no patients with severe anxiety. On the other hand, percentages of subjects who had minimal and mild levels of anxiety increased to $60.0 \%$ and $26.0 \%$ respectively.

It was also noted that the difference between levels of anxiety among the studied subjects before and after the SSBM was statistically significant $(\mathrm{p}=0.019)$. The mean score of PSA significantly improved by a percentage of $30.34 \pm 42.85$, where the mean score was $13.3 \pm 8.9$ before the SSBM and significantly decreased to $8.2 \pm 5.6$ after applying it $(\mathrm{p}=0.003)$.

Table (5) shows that there were no statistically significant relationships between all subjects' socio-demographic characteristics, social activities and habits, and the mean percent change of both PSD and PSA levels after applying the SSBM ( $p>0.05)$. However, it was noticed that the highest mean percent change of PSD after receiving SSBM was obtained by subjects aged 65 to less than 70 years $(36.84 \pm 18.61)$, were widowed $(28.15 \pm 38.23)$, read and write $(40.41 \pm 32.42)$, manual workers $(31.11 \pm 34.15)$, living in own home with their family $(28.76 \pm 25.41)$, had previous recreational activities and hobbies 
(26.59 \pm 25.44$)$ and those who were current smokers $(29.27 \pm 26.25)$, for a duration of 30 years and more (29.47 \pm 25.74$)$, and those who smoked shisha (34.36 \pm 26.92$)$.

Regarding PSA, it was observed that the highest mean percent change of anxiety after applying the SSBM was obtained by subjects who aged 65 to less than 70 years (44.26 \pm 15.14$)$, were married $(34.55 \pm 32.23)$, had intermediate education (diploma) (42.84 \pm 4.0$)$, employees $(37.98 \pm 27.83)$, living with a relatives in his home $(50.0 \pm 0.0)$, had no previous recreational activities and hobbies (44.50 \pm 27.58$)$, were current smokers $(33.72 \pm 43.70)$, for a duration of 10 to less than 20 years $(75.0 \pm 0.0)$, and those who smoked cigarettes (34.02 \pm 31.62$)$.

Table (6) illustrates that there were no statistically significant relationships between all subjects' health status and clinical characteristics, and the mean percent change of both PSD and PSA levels after applying SSBM ( $>>0.05)$. Yet, it was noted that after undergoing the study intervention the highest mean percent change of PSD was obtained by subjects who had normal cognitive functioning $(30.13 \pm 27.70)$, no chronic diseases other than stroke $(33.33 \pm 0.0)$, intra-cerebral hemorrhage $(54.55 \pm 0.0)$, for the first time $(27.56 \pm 26.11)$, in the right side (27.55 \pm 28.02$)$, for a duration of 15 days and more $(40.35 \pm 32.24)$ and had no strokerelated medical complications (30.95 \pm 32.45$)$.

As for PSA, it was observed that the highest mean percent change of anxiety after applying the SSBM was obtained by subjects who had mild cognitive functioning (33.40 \pm 30.79$)$, no chronic diseases other than stroke $(33.33 \pm 0.0)$, ischemic embolic type of stroke $(35.13 \pm 32.05)$, for the first time $(32.89 \pm 43.18)$, in the left side (33.71 \pm 28.44$)$, for a duration of 15 days and more $(25.84 \pm 41.63)$ and had no strokerelated medical complications (40.48 \pm 32.08$)$.

\section{Discussion}

Age is a principal non-modifiable risk factor for stroke ${ }^{(6)}$. chronic diseases, such as hypertension, coronary artery diseases, diabetes mellitus, and hyperlipidemia, are also other common risk factors of developing stroke among older adults ${ }^{(7,14)}$. In the same direction, the findings of the present study indicated that the age of the studied subjects ranged from 60 to 89 years, with a mean age of $65.6 \pm 6.2$ years (table 1 ). The results also revealed that the majority of subjects suffered from co-morbid chronic diseases other than stroke. More than three quarters of these patients suffered from hypertension, while nearly a half of them had hyperlipidemia, and more than one third of patients had diabetes mellitus (table 2).

As well, it was reported that risky behaviors, such as smoking, are associated with developing stroke ${ }^{(12)}$. This goes with the findings of the present study where most of the studied subjects were ex-smokers. The majority of the studied patients reported that they used to smoke for 30 years and more (table 1).

Early management and effective nursing care may have a positive impact on functional and psychosocial outcomes of post-stroke patients ${ }^{(23,25)}$. Research has validated that depression and anxiety are influenced by multiple doses of therapeutic massage $e^{(19,22)}$. On that base, it was advocated that one of the most creative nursing interventions that can be useful for post-stroke geriatric patients is the SSBM $^{(23,24,28)}$. Accordingly, the present study hypothesized that post-stroke geriatric patients who received slow stroke back massage exhibited lower levels of depression and anxiety than before receiving it. This hypothesis was proved by the results of the current study which indicate significant reductions in the mean scores of PSD and PSA following the SSBM. More specifically, the percentages of subjects who had moderate and severe levels of depression significantly decreased after applying the SSBM (table 3). 
Furthermore, the percentage of those who had moderate level of anxiety significantly decreased, while no patient was found to have severe anxiety after receiving the SSBM (table 4).

These results are in harmony with the findings of previous studies which demonstrated the effectiveness of SSBM in lowering levels of depression and anxiety among elderly patients ${ }^{(11,20,25,28)}$. Thus, Harris et al. (2010) reviewed all studies which examined the physiological and psychological effects of SSBM and hand massage on relaxation in older people. They found that using SSBM and hand massage showed statistically significant improvements on physiological and psychological indicators of relaxation ${ }^{(28)}$. More recently, Erol et al. (2014) stated that hand massage was significantly effective in reducing levels of depression rates among the elderly. The researchers attributed their results to the effect of massage in reducing tension and ensuring physical and mental relaxation $^{(20)}$. In addition, Mok and Woo (2004) explored the effect of SSBM on anxiety in hospitalized elderly patients with stroke. Their results revealed that the massage intervention significantly reduced the patients' level of anxiety. Thereby, authors suggested that the SSBM is an effective nursing intervention which provides an opportunity for nurses to decrease post-stroke geriatric patients' level of anxiety and provide them with more individualized and holistic care ${ }^{(25)}$.

It is worth mentioning here that mood changes were recorded in patients' charts as a functional decline among about two thirds of the subjects in the current study (table 2). In order to validate the presence of these psychological problems; before applying the SSBM, the subjects were asked about their emotional status. It appeared that these symptoms of depression and anxiety were problematic enough to patients, as their answers revealed that most of them feel sad and uncomfortable, more than two thirds of them felt anxious, and more than half of the patients felt helpless. These findings are in accordance with those of Campbell Burton et al. (2013) who reported that over one half of the patients felt anxious and two thirds reported concerns about their disability after stroke ${ }^{(38)}$. Evidence suggests that these negative feelings may be related to many common patients' worries about having another stroke, being unable to communicate or to get help, being unable to return to work, side-effects of medication, falling, feeling embarrassed in social situations, and never feeling any better ${ }^{(5)}$.

The obvious improvements in the current study subjects' levels of PSD and PSA following the SSBM can be attributed to certain factors. One of these factors could be the beneficial effect of massage therapy in reducing muscle tension and relieving stress. In this case, massage might be considered as a beneficial therapeutic tool for improving patient's psychological wellbeing by progressively increasing mental relaxation and consequently decreasing post-stroke symptoms of depression and anxiety. In the same line, Olney (2007) found that depression and anxiety changed significantly with the application of therapeutic massage ${ }^{(19)}$.

Another factor that may contribute to the reduced patients' levels of PSD and PSA after receiving SSBM is the interpersonal therapist-patient relationship and therapeutic communication that take place during the therapy. While the SSBM is applied, an open dialogue between the patient and a professional nurse is conducted. Through this accepting and supportive atmosphere, post-stroke patients may feel respected and empowered, so they can express their feelings and concerns to someone who supports, empathetically listens and understands. In this situation, such feelings of depression and anxiety can be alleviated in the context of a caring interpersonal relationship. In support of this explanation, Boulanger and Campo (2013) assumed that the interpersonal behaviors of a healthcare provider can influence the 
outcomes of patients receiving complementary and alternative interventions such as massage therapy ${ }^{(39)}$. This assumption goes in harmony with the findings obtained by Holland and Pokorny (2001) who found that patients perceived SSBM as being comfortable, pleasant, and relaxed. These responses indicated that this enjoyable intervention made the patients feel cared for, happy, physically relaxed, less anxious, calm, restful, and gave them a feeling of closeness with the nurse ${ }^{(23)}$.

In addition, Moyer et al. (2004) stated that communication, the interpersonal contact and the amount of empathy perceived by the patient on behalf of the therapist are considered to influence outcomes of massage therapy ${ }^{(22)}$. Olney (2007) concluded that the perceived rapport and intimacy of massage which are developed within the therapeutic relationship can provide the benefits of reductions in anxiety and depression ${ }^{(19)}$.

The impact of therapeutic touch can also explain the results of this study. It is a widely known fact that massage reduces muscle tension and evokes relaxation response through the physical contact, namely; touch ${ }^{(20)}$. Therapeutic touch is the fundamental medium of massage therapy. Yet, it is not used solely in a mechanic way in massage therapy. When used with sensitivity, touch allows the massage therapist to receive useful information via his or her hands about the patient's body, such as locating areas of tension and other soft tissue problems. Moreover, sensitive touch is a form of communication. It can convey a sense of caring and support which are essential elements in the therapeutic nurse-patient relationship ${ }^{(21)}$. This approach may add to the intimacy between the therapist and the patients, enabling them to feel valued, understood and probably relieved from negative feelings of depression and anxiety. This explanation has been claimed in another study which emphasized the significant effects of touch on anxiety and depression ${ }^{(19)}$.
Additionally, post-stroke shoulder pain and motor function impairment are common problems following stroke. They result in physical handicaps and limitations in activities of daily living (ADL) ${ }^{(17,40)}$. Poststroke elderly patients may find themselves disable, dependent. They lose many of their hopes and plans, and have to adapt to changed social roles. All these are possible risk factors of developing of PSD and PSA $^{(5,6,17)}$. Prior studies have also found a positive correlation between higher shoulder pain intensity, and worse levels of both depression and anxiety. This intense shoulder pain might lead the patient to feel stressed, anxious and probably depressed $^{(20,25)}$. Other several studies suggested that the SSBM can be applied effectively to decrease the severity of poststroke shoulder pain and consequently induce sleep, promote mental relaxation and well-being and reduce levels of anxiety and depression ${ }^{(11,20,24,25,28)}$. According to the findings of Atashi et al. (2012), the SSBM along with physical exercise were effective in reducing shoulder pain, improving overall motor function and alleviating anxiety in post-stroke patients ${ }^{(41)}$. Accordingly, improvements in mean levels, mean scores and mean percent change of PSD (table 3) and PSA (table 4) among patients in the present study could be indirectly attributed to the positive effect of SSBM on reducing post-stroke patients' shoulder pain, improving motor function, and optimizing independence and overall functional ability which consequently improve their psychosocial condition.

Nevertheless, the results of the present study demonstrated that there was no significant relationship between all subjects' socio-demographic characteristics, social activities, habits, health status and clinical characteristics, and the mean percent change of PSD and PSA after applying the SSBM (tables 5 and 6). This result is in contrast with findings of numerous studies which reported significant positive correlations between subjects' socio-demographic and clinical characteristics (such as age, 
functional decline, having chronic comorbid conditions and stroke-related complications), and their levels of PSD and $\operatorname{PSA}^{(7,9,17,42-45)}$.

The findings of the current research revealed that although relationships between all subjects' socio-demographic and clinical characteristics, and the mean percent change of PSD and PSA after applying the SSBM were statistically insignificant, yet; it seems in some cases that these patients' characteristics could play a role in their response to the study intervention. This means that subjects with certain sociodemographic and clinical characteristics achieved improvement in the levels of PSD and PSA after receiving the SSBM than other subjects. For example, subjects aged 65 to less than 70 years achieved lower levels of PSD and PSA after the SSBM than other subjects in different age groups (table 5 ). This finding can be rationalized by the fact that subjects in the age group between 65 to less than 70 years constituted a small proportion of the study sample, so mean scores of PSD and PSA can be easily affected by extreme heterogeneous scores of depression and anxiety. This finding is supported and is generally consistent with similar findings of previous studies which indicated that younger elderly (60-70 years) appear to have a better prognosis than older elderly patients $(70+$ years) after receiving effective post-stroke interventions ${ }^{(42,43)}$. It was also found that subjects who had stroke for the first time, for duration of 15 days and more, and had no chronic diseases other than stroke or stroke-related medical complications achieved lower levels of PSD and PSA after the SSBM than other subjects (table 6). The same findings are almost obtained by other studies ${ }^{(17,45)}$.

\section{Conclusion}

Based on the results of this study, it can be concluded that the SSBM is a clinically effective complementary nursing intervention that can significantly reduce levels of depression and anxiety among post-stroke geriatric patients.

\section{Recommendations}

The following recommendations are suggested:

- Including the SSBM as an integral part in the gerontological and psychiatric nursing courses.

- Developing skill-based training programs for all nurses working in neurological and psychiatric units about knowledge and skills of applying the SSBM for post-stroke geriatric patients.

- Developing a training program for caregivers of post-stroke geriatric patients including knowledge and skills of the SSBM.

- Further researches are needed to evaluate the stability of long-term effects of the SSBM. 
Table (1): Socio-demographic characteristics, social activities and habits of the studied subjects

\begin{tabular}{|c|c|c|}
\hline \multirow{2}{*}{$\begin{array}{l}\text { Socio-demographic characteristics, social activities } \\
\text { and habits }\end{array}$} & \multicolumn{2}{|c|}{$(n=50)$} \\
\hline & No. & $\%$ \\
\hline \multicolumn{3}{|l|}{ Age (in years) } \\
\hline $60-$ & 32 & 64.0 \\
\hline $65-$ & 7 & 14.0 \\
\hline $70+$ & 11 & 22.0 \\
\hline Min. -Max. & \multirow{2}{*}{\multicolumn{2}{|c|}{$\begin{array}{c}60.0-89.0 \text { years } \\
65.64 \pm 6.19\end{array}$}} \\
\hline Mean $\pm S D$ & & \\
\hline \multicolumn{3}{|l|}{ Marital Status } \\
\hline Married & 40 & 80.0 \\
\hline Widowed & 9 & 18.0 \\
\hline Divorced & 1 & 2.0 \\
\hline \multicolumn{3}{|l|}{ Educational level } \\
\hline Illiterate & 19 & 38.0 \\
\hline Read and write & 10 & 20.0 \\
\hline Basic education (primary and preparatory) & 8 & 16.0 \\
\hline Secondary education & 9 & 18.0 \\
\hline Intermediate education (diploma) & 4 & 8.0 \\
\hline \multicolumn{3}{|l|}{ Occupation before retirement } \\
\hline Manual worker & 31 & 62.0 \\
\hline Employee & 12 & 24.0 \\
\hline Private job & 7 & 14.0 \\
\hline \multicolumn{3}{|l|}{ Living conditions } \\
\hline Live in own home with their family & 45 & 90.0 \\
\hline Live alone in own home & 4 & 8.0 \\
\hline Live with a relative in his home & 1 & 2.0 \\
\hline \multicolumn{3}{|l|}{ Having previous recreational activities and hobbies } \\
\hline Yes & 48 & 96.0 \\
\hline No & 2 & 4.0 \\
\hline \multirow{2}{*}{$\begin{array}{l}\text { Type of recreational activity } \\
\text { Going to café and meeting friends }\end{array}$} & \multicolumn{2}{|c|}{$(n=48)$} \\
\hline & 33 & 68.8 \\
\hline Playing cards, chess or dominoes & 11 & 22.9 \\
\hline Reading & 4 & 8.3 \\
\hline \multicolumn{3}{|l|}{ Smoking history: } \\
\hline \multicolumn{3}{|l|}{ Smoking status } \\
\hline Ex-smoker & 35 & 70.0 \\
\hline Current smoker & 12 & 24.0 \\
\hline Non-smoker & 3 & 6.0 \\
\hline Duration of smoking (in years) & \multicolumn{2}{|c|}{$(n .=47)$} \\
\hline $10-$ & 1 & 2.1 \\
\hline $20-$ & 4 & 8.5 \\
\hline $30+$ & 42 & 89.4 \\
\hline $\begin{array}{l}\text { Min. }- \text { Max. } \\
\text { Mean } \pm S D\end{array}$ & \multicolumn{2}{|c|}{$\begin{array}{l}10.0-50.0 \text { years } \\
3781+9.45\end{array}$} \\
\hline Type of smoking & \multicolumn{2}{|c|}{$(n .=47)$} \\
\hline Cigarettes & 39 & 83.0 \\
\hline Shisha & 8 & 17.0 \\
\hline
\end{tabular}


Table (2): Health status and clinical characteristics of the studied subjects

\begin{tabular}{|c|c|c|}
\hline \multirow{2}{*}{ Health status and clinical characteristics } & \multicolumn{2}{|c|}{$(n=50)$} \\
\hline & No. & $\%$ \\
\hline \multicolumn{3}{|l|}{ Cognitive status as measured by MMSE } \\
\hline Normal cognitive functioning & 27 & 54.0 \\
\hline Mild cognitive impairment & 23 & 46.0 \\
\hline \multicolumn{3}{|l|}{ Presence of chronic diseases other than stroke } \\
\hline Yes & 49 & 98.0 \\
\hline No & 1 & 2.0 \\
\hline \multicolumn{3}{|l|}{ Type of chronic disease } \\
\hline Hypertension & 38 & 76.0 \\
\hline Hyperlipidemia & 24 & 48.0 \\
\hline Diabetes mellitus & 19 & 38.0 \\
\hline Chest pain (CAD) & 15 & 30.0 \\
\hline Cardiac valves diseases & 4 & 8.0 \\
\hline Osteoarthritis & 3 & 6.0 \\
\hline Chronic GIT disease & 3 & 6.0 \\
\hline Chronic liver diseases & 2 & 4.0 \\
\hline Renal diseases & 2 & 4.0 \\
\hline Arrhythmias & 1 & 2.0 \\
\hline \multicolumn{3}{|c|}{$\begin{array}{l}\text { Currently prescribed medications as recorded in patient's } \\
\text { chart }\end{array}$} \\
\hline Phospho-disterase inhibitors (Trental) & 48 & 96.0 \\
\hline Heparinzation and antiplatelet regression drugs & 44 & 88.0 \\
\hline Anti-hypertensive drugs & 41 & 82.0 \\
\hline Lipids lowering drugs & 41 & 82.0 \\
\hline Nutritional supplements & 37 & 72.0 \\
\hline Antacids & 27 & 54.0 \\
\hline Laxatives & 17 & 34.0 \\
\hline Antibiotics & 13 & 26.0 \\
\hline Oral hypoglycemic agents & 13 & 26.0 \\
\hline Insulin & 5 & 10.0 \\
\hline Bronchiodilators (Atrovent) & 1 & 2.0 \\
\hline Anti-convulsive agents (Carbamazepine) & 1 & 2.0 \\
\hline \multicolumn{3}{|l|}{ Patient's emotional status in the hospital: } \\
\hline \multicolumn{3}{|l|}{ Feeling sad and uncomfortable } \\
\hline Yes & 41 & 82.0 \\
\hline No & 9 & 18.0 \\
\hline \multicolumn{3}{|l|}{ Feeling anxious } \\
\hline Yes & 34 & 68.0 \\
\hline No & 16 & 32.0 \\
\hline \multicolumn{3}{|l|}{ Feeling helpless } \\
\hline Yes & 29 & 58.0 \\
\hline No & 21 & 42.0 \\
\hline
\end{tabular}

\# Frequencies are not mutually exclusive. 
Table (2): (continued).

\begin{tabular}{|c|c|c|}
\hline \multirow{2}{*}{ Health status and clinical characteristics } & \multicolumn{2}{|c|}{$(\mathbf{n}=\mathbf{5 0})$} \\
\hline & No. & $\%$ \\
\hline \multicolumn{3}{|l|}{ Stroke-related data: } \\
\hline \multicolumn{3}{|l|}{ Type of stroke } \\
\hline Ischemic Thrombotic & 30 & 60.0 \\
\hline Ischemic Lacunar & 10 & 20.0 \\
\hline Ischemic Embolic & 9 & 18.0 \\
\hline Intra-cerebral Hemorrhage & 1 & 2.0 \\
\hline \multicolumn{3}{|l|}{ Onset of stroke } \\
\hline First time & 44 & 88.0 \\
\hline Recurrent stroke & 6 & 12.0 \\
\hline \multicolumn{3}{|l|}{ Affected side } \\
\hline Right & 29 & 58.0 \\
\hline Left & 21 & 42.0 \\
\hline \multicolumn{3}{|l|}{ Duration of being diagnosed with stroke (in days) } \\
\hline $3-$ & 32 & 64.0 \\
\hline $7-$ & 10 & 20.0 \\
\hline $15+$ & 8 & 16.0 \\
\hline Min. - Max. & \multirow{2}{*}{\multicolumn{2}{|c|}{$\begin{array}{c}3.0-21.0 \text { days } \\
762+3.6\end{array}$}} \\
\hline Mean $\pm S D$ & & \\
\hline \multicolumn{3}{|l|}{ Type of functional decline (as recorded in patient's chart) } \\
\hline Hemiparesis & 44 & 88.0 \\
\hline Mood changes & 33 & 66.0 \\
\hline Sensory loss & 31 & 62.0 \\
\hline Communication problems & 30 & 60.0 \\
\hline Dysphagia & 8 & 16.0 \\
\hline Hemiplagia & 6 & 12.0 \\
\hline \multicolumn{3}{|l|}{ Presence of stroke-related medical complications } \\
\hline Yes & 39 & 78.0 \\
\hline No & 11 & 22.0 \\
\hline \multicolumn{3}{|l|}{ Type of stroke-related complication } \\
\hline Constipation & 26 & 56.0 \\
\hline Urinary incontinence & 12 & 30.8 \\
\hline Urinary tract infection & 7 & 17.9 \\
\hline Pneumonia & 6 & 15.4 \\
\hline Falls & 4 & 10.3 \\
\hline Arrhythmias & 1 & 2.6 \\
\hline Brain edema & 1 & 2.6 \\
\hline Seizures & 1 & 2.6 \\
\hline
\end{tabular}

\# Frequencies are not mutually exclusive. 
Slow Stroke Back Massage on Post-Stroke Depression and Anxiety

Table (3): Study subjects' levels and mean scores of PSD before and after the intervention, and its mean percent change after applying $\operatorname{SSBM}(n=50)$

\begin{tabular}{|c|c|c|c|c|c|}
\hline \multirow[t]{2}{*}{ Levels of PSD } & \multicolumn{2}{|c|}{$\begin{array}{c}\text { Before applying } \\
\text { SSBM }\end{array}$} & \multicolumn{2}{|c|}{$\begin{array}{c}\text { After applying } \\
\text { SSBM }\end{array}$} & \multirow[t]{2}{*}{ Test of significance } \\
\hline & No & $\%$ & No & $\%$ & \\
\hline No depression & 21 & 42.0 & 30 & 60.0 & \multirow{4}{*}{$M c p=0.048^{*}$} \\
\hline Mild depression & 12 & 24.0 & 14 & 28.0 & \\
\hline Moderate depression & 8 & 16.0 & 2 & 4.0 & \\
\hline \multirow[t]{3}{*}{ Severe depression } & 9 & 18.0 & 4 & 8.0 & \\
\hline & \multicolumn{2}{|c|}{ Mean \pm SD } & \multicolumn{2}{|c|}{ Mean \pm SD } & Mean \% Change \pm SD \\
\hline & \multicolumn{2}{|c|}{$6.34 \pm 4.26$} & \multicolumn{2}{|c|}{$4.36 \pm 3.32$} & $26.41 \pm 25.33$ \\
\hline Test of significance & \multicolumn{4}{|c|}{$p=0.025$} & \\
\hline
\end{tabular}

Mc p: Exact Mc-Nemar test

\#: Wilcoxon test

*: Statistically significant at $\mathrm{p} \leq 0.05$.

Table (4) Study subjects' levels and mean scores of PSA before and after the intervention, and its mean percent change after applying $\operatorname{SSBM}(n=50)$

\begin{tabular}{|c|c|c|c|c|c|}
\hline \multirow[t]{2}{*}{ Levels of PSA } & \multicolumn{2}{|c|}{$\begin{array}{c}\text { Before applying } \\
\text { SSBM }\end{array}$} & \multicolumn{2}{|c|}{$\begin{array}{c}\text { After applying } \\
\text { SSBM }\end{array}$} & \multirow[t]{2}{*}{ Test of significance } \\
\hline & No & $\%$ & No & $\%$ & \\
\hline Minimal anxiety & 20 & 40.0 & 30 & 60.0 & \multirow{4}{*}{$M c p=0.019 *$} \\
\hline Mild anxiety & 12 & 24.0 & 13 & 26.0 & \\
\hline Moderate anxiety & 11 & 22.0 & 7 & 14.0 & \\
\hline \multirow[t]{3}{*}{ Severe anxiety } & 7 & 14.0 & 0 & 0.0 & \\
\hline & \multicolumn{2}{|c|}{ Mean \pm SD } & \multicolumn{2}{|c|}{ Mean \pm SD } & Mean \% Change \pm SD \\
\hline & \multicolumn{2}{|c|}{$13.3 \pm 8.9$} & \multicolumn{2}{|c|}{$8.2 \pm 5.6$} & $30.34 \pm 42.85$ \\
\hline Test of significance & \multicolumn{4}{|c|}{$p=0.003$} & \\
\hline
\end{tabular}

Mc p: Exact Mc-Nemar test

\#: Wilcoxon test

*: Statistically significant at $\mathrm{p} \leq 0.05$.

**: Statistically significant at $\mathrm{p} \leq 0.01$ 
Slow Stroke Back Massage on Post-Stroke Depression and Anxiety

Table (5): Relationship between subjects' socio-demographic characteristics, social activities and habits, and their mean percent change of both PSD and PSA levels after applying $\operatorname{SSBM}(\mathbf{n}=\mathbf{5 0})$

\begin{tabular}{|c|c|c|}
\hline \multirow{2}{*}{$\begin{array}{l}\text { Socio-demographic characteristics, social activities } \\
\text { and habits }\end{array}$} & \multicolumn{2}{|c|}{ Mean \% Change \pm SD } \\
\hline & Level of PSD & Level of PSA \\
\hline \multicolumn{3}{|l|}{ Age (in years) } \\
\hline $60-$ & $25.38 \pm 28.90$ & $28.63 \pm 49.43$ \\
\hline $65-$ & $36.84 \pm 18.61$ & $44.26 \pm 15.14$ \\
\hline $70+$ & $23.86 \pm 17.16$ & $27.97 \pm 32.72$ \\
\hline Test of significance $F(p)$ & $0.585(0.561)$ & $0.351(0.706)$ \\
\hline \multicolumn{3}{|l|}{ Marital Status } \\
\hline Married & $27.39 \pm 23.26$ & $34.55 \pm 32.23$ \\
\hline Widowed & $28.15 \pm 38.23$ & $9.99 \pm 86.24$ \\
\hline Divorced & $9.52 \pm 16.50$ & $21.82 \pm 22.78$ \\
\hline Test of significance $F(p)$ & $0.704(0.500)$ & $1.043(0.360)$ \\
\hline \multicolumn{3}{|l|}{ Educational level } \\
\hline Illiterate & $28.58 \pm 23.42$ & $35.41 \pm 30.16$ \\
\hline Read and write & $40.41 \pm 32.42$ & $25.48 \pm 43.36$ \\
\hline Basic education (primary \& preparatory) & $15.36 \pm 27.65$ & $11.70 \pm 80.14$ \\
\hline Secondary education & $21.31 \pm 20.02$ & $36.08 \pm 30.11$ \\
\hline Intermediate education (diploma) & $18.15 \pm 14.40$ & $42.84 \pm 4.0$ \\
\hline Test of significance $F(p)$ & $1.337(0.271)$ & $0.582(0.677)$ \\
\hline \multicolumn{3}{|l|}{ Occupation before retirement } \\
\hline Manual worker & $31.11 \pm 34.15$ & $17.11 \pm 69.50$ \\
\hline Employee & $24.77 \pm 23.62$ & $37.98 \pm 27.83$ \\
\hline Private job & $26.28 \pm 18.59$ & $19.19 \pm 38.40$ \\
\hline Test of significance $F(p)$ & $0.247(0.782)$ & $1.319(0.277)$ \\
\hline \multicolumn{3}{|l|}{ Living conditions } \\
\hline Live in own home with their family & $28.76 \pm 25.41$ & $30.41 \pm 44.81$ \\
\hline Live alone in own home & $7.14 \pm 14.29$ & $24.70 \pm 19.47$ \\
\hline Live with a relative in his home & $0.0 \pm 0.0$ & $50.0 \pm 0.0$ \\
\hline Test of significance $F(p)$ & $1.966(0.152)$ & $0.135(0.874)$ \\
\hline \multicolumn{3}{|l|}{ Having previous recreational activities and hobbies } \\
\hline Yes & $26.59 \pm 25.44$ & $29.75 \pm 43.47$ \\
\hline No & $22.22 \pm 31.43$ & $44.50 \pm 27.58$ \\
\hline Test of significance $t(p)$ & $0.236(0.814)$ & $0.473(0.638)$ \\
\hline \multicolumn{3}{|l|}{ Smoking history: } \\
\hline \multicolumn{3}{|l|}{ Smoking status } \\
\hline Ex-smoker & $0.0 \pm 0.0$ & $27.88 \pm 32.54$ \\
\hline Current smoker & $29.27 \pm 26.25$ & $33.72 \pm 43.70$ \\
\hline Non-smoker & $24.49 \pm 22.22$ & $21.11 \pm 44.22$ \\
\hline Test of significance $F(p)$ & $1.962(0.152)$ & $0.382(0.684)$ \\
\hline \multicolumn{3}{|l|}{ Duration of smoking (in years) } \\
\hline $10-$ & $0.0 \pm 0.0$ & $75.0 \pm 0.0$ \\
\hline $20-$ & $21.43 \pm 18.44$ & $45.98 \pm 4.41$ \\
\hline $30+$ & $29.47 \pm 25.74$ & $27.97 \pm 45.42$ \\
\hline Test of significance $\vec{F}(p)$ & $0.816(0.449)$ & $0.834(0.441)$ \\
\hline \multicolumn{3}{|l|}{ Type of smoking } \\
\hline Cigarettes & $26.82 \pm 25.0$ & $34.02 \pm 31.62$ \\
\hline Shisha & $34.36 \pm 26.92$ & $13.35 \pm 81.96$ \\
\hline Test of significance t $(p)$ & $0.765(0.448)$ & $0.703(0.504)$ \\
\hline
\end{tabular}


Table (6): Relationship between subjects' health status and clinical characteristics, and their mean percent change of levels of both PSD and PSA after applying SSBM $(n=50)$

\begin{tabular}{|c|c|c|}
\hline \multirow{2}{*}{ Health status and clinical characteristics } & \multicolumn{2}{|c|}{ Mean \%Change \pm SD } \\
\hline & Level of PSD & Level of PSA \\
\hline \multicolumn{3}{|l|}{ Cognitive status as measured by MMSE } \\
\hline Normal cognitive functioning & $30.13 \pm 27.70$ & $27.74 \pm 51.41$ \\
\hline Mild cognitive impairment & $22.20 \pm 22.20$ & $33.40 \pm 30.79$ \\
\hline Test of significance $t(p)$ & $1.095(0.279)$ & $0.462(0.646)$ \\
\hline \multicolumn{3}{|l|}{ Presence of chronic diseases other than stroke } \\
\hline Present & $26.26 \pm 25.58$ & $30.28 \pm 43.30$ \\
\hline Not present & $33.33 \pm 0.0$ & $33.33 \pm 0.0$ \\
\hline Test of significance $t(p)$ & $0.274(0.786)$ & $0.070(0.945)$ \\
\hline \multicolumn{3}{|l|}{ Stroke-related data: } \\
\hline \multicolumn{3}{|l|}{ Type of stroke } \\
\hline Ischemic Thrombotic & $22.11 \pm 23.25$ & $29.01 \pm 48.97$ \\
\hline Ischemic Lacunar & $27.05 \pm 22.20$ & $30.09 \pm 36.48$ \\
\hline Ischemic Embolic & $38.19 \pm 34.27$ & $35.13 \pm 32.05$ \\
\hline Intra-cerebral Hemorrhage & $54.55 \pm 0.0$ & $30.0 \pm 0.0$ \\
\hline Test of significance $F(p)$ & $1.303(0.285)$ & $0.044(0.987)$ \\
\hline \multicolumn{3}{|l|}{ Onset of stroke } \\
\hline First time & $27.56 \pm 26.11$ & $32.89 \pm 43.18$ \\
\hline Recurrent stroke & $18.13 \pm 18.37$ & $11.64 \pm 38.55$ \\
\hline Test of significance $t(p)$ & $0.852(0.399)$ & $1.143(0.259)$ \\
\hline \multicolumn{3}{|l|}{ Affected side } \\
\hline Right & $27.55 \pm 28.02$ & $27.91 \pm 51.20$ \\
\hline Left & $24.88 \pm 21.81$ & $33.71 \pm 28.44$ \\
\hline Test of significance $t(p)$ & $0.361(0.720)$ & $0.469(0.641)$ \\
\hline \multicolumn{3}{|l|}{$\begin{array}{l}\text { Duration of being diagnosed with stroke (in } \\
\text { days) }\end{array}$} \\
\hline $3-$ & $31.14 \pm 33.17$ & $16.21 \pm 66.5$ \\
\hline $7-$ & $15.24 \pm 25.56$ & $11.60 \pm 75.13$ \\
\hline $15+$ & $40.35 \pm 32.24$ & $25.84 \pm 41.63$ \\
\hline Test of significance $F(p)$ & $1.522(0.229)$ & $0.110(0.896)$ \\
\hline \multicolumn{3}{|l|}{ Type of functional decline } \\
\hline Hemiparesis & $28.51 \pm 21.13$ & $33.17 \pm 42.21$ \\
\hline Mood changes & $32.65 \pm 36.74$ & $35.16 \pm 53.12$ \\
\hline Sensory loss & $30.52 \pm 16.40$ & $31.18 \pm 24.19$ \\
\hline Communication problem & $31.29 \pm 17.94$ & $30.19 \pm 28.53$ \\
\hline Dysphagia & $38.29 \pm 34.21$ & $35.31 \pm 32.56$ \\
\hline Hemiplagia & $19.14 \pm 18.31$ & $12.43 \pm 36.45$ \\
\hline Test of significance $F(p)$ & $0.523(0.759)$ & $0.380(0.862)$ \\
\hline \multicolumn{3}{|l|}{ Presence of stroke-related medical complications } \\
\hline Present & $25.24 \pm 23.54$ & $27.49 \pm 45.38$ \\
\hline Not present & $30.95 \pm 32.45$ & $40.48 \pm 32.08$ \\
\hline Test of significance $t(p)$ & $0.632(0.530)$ & $0.886(0.380)$ \\
\hline
\end{tabular}




\section{References}

1. World Health Organization. Stroke, Cerebrovascular accident. 2013. Available at: http://www.who.int/topics/cerebrovascu lar_accident/en/. (Retrieved on: 10/11/2013).

2. Irish Heart Foundation \& National Stroke Support Group Network. Experiences and long-term needs reported by stroke survivors living in the community in Ireland. 2014. Available at: http://www.stroke.ie/media/pub/advoca cy/web_version_community_stroke_re port_march_2014.pdf. (Retrieved on: 25/6/2015).

3. Davenport R, Dennis M, Wellwood I, Warlow C. Complications after acute stroke. Stroke 1996; 27(3): 415-20.

4. Kneebone I, Lincoln N. Psychological problems after stroke and their management: State of knowledge. Neuroscience \& Medicine 2012; 3: 839.

5. Stroke Association. Emotional changes after stroke. 2012. Available at: http://www.stroke.org.uk/sites/default/fi les/Emotional\%20changes\%20after\%20 stroke.pdf. (Retrieved on: 25/6/2015).

6. Barker-Collo S. Depression and anxiety 3 months post stroke: prevalence and correlates. Archives of Clinical Neuropsychology 2007; 22(4): 519-31.

7. Stroke Foundation. Depression and anxiety after stroke. 2008. Available at: http://resources.beyondblue.org.auprism/file/token=BL.0115.pdf. (Retrieved on: 25/6/2015).

8. Stuart G. Principles and practice of psychiatric nursing. 10th ed. St Louis: Mosby, Elsevier Inc., 2013.

9. Broomfield N, Quinn T, Abdul-Rahim A, Walters M, Evans J. Depression and anxiety symptoms post-stroke/TIA: prevalence and associations in cross- sectional data from a regional stroke registry. BMC Neurology 2014, 14:198. Available at: http://www.biomedcentral.com/14712377/14/198. (Retrieved on: 25/6/2015).

10. Angelelli P, Paolucci S, Bivona U, Piccardi L, Ciurli P, Cantagallo A, Antonucci G, Fasotti L, Di Santantonio A, Grasso M, Pizzamiglio L. Development of neuropsychiatric symptoms in poststroke patients: a cross-sectional study. Acta Psychiatrica Scandinavica 2004; 110(1): 55-63.

11. Campbell Burton C, Holmes J, Murray J, Gillespie D, Lightbody C, Watkins C, Knapp P. Interventions for treating anxiety after stroke. Cochrane Database of Systematic Reviews 2011; 7(12):CD008860. Available at: http://onlinelibrary.wiley.com/store/10.1 002/14651858.CD008860.pub2/asset/C D008860.pdf? $\mathrm{v}=1 \& \mathrm{t}=$ iemhjp60\&s $=795$ 9265451b2a166cf53caf6efcfd44d45940 0e4. (Retrieved on: 20/2/2015).

12. Khedr E, Elfetoh N, Al Attar G, Ahmed M, Ali A, Hamdy A, Kandil M, Farweez H. Epidemiological study and risk factors of stroke in Assiut Governorate, Egypt: community-based study. Neuroepidemiology 2013; 40(4): 288-94.

13. Kimura M, Tateno A, Robinson R. Treatment of poststroke generalized anxiety disorder comorbid with poststroke depression: merged analysis of nortriptyline trials. American Journal of Geriatric Psychiatry 2003; 11(3):3207.

14. Masskulpan P, Riewthong K, Dajpratham P, Kuptniratsaikul V. Anxiety and depressive symptoms after stroke in 9 rehabilitation centers. Journal of the Medical Association of Thailand 2008; 91(10): 1595-602.

15. Lökk J, Delbari A. Management of depression in elderly stroke patients. Neuropsychiatric Disease and Treatment 2010; 6: 539-49. 
16. Pohjasvaara T, Vataja R, Leppävuori A, Kaste M, Erkinjuntti T. Depression is an independent predictor of poor long-term functional outcome post-stroke. European Journal Neurology 2001; 8(4): 315-9.

17. Khan F. Poststroke depression. Australian Family Physician 2004; 33(10): 831-4.

18. Hackett M, Anderson C, House A. Interventions for treating depression after stroke (Review). Cochrane Database of Systematic Reviews 2004; (3):CD003437. Available at: http://onlinelibrary.wiley.com/store/10.1 002/14651858.CD003437.pub2/asset/C D003437.pdf? $\mathrm{v}=1 \& \mathrm{t}=$ iepgr0gw \&s $=381$ 04b92049b6e8f758e721223b81dafa315 e94f. (Retrieved on: 20/2/2015).

19. Olney C. Back massage: Long term effects and dosage determination for persons with pre-hypertension and hypertension. University of South Florida, 2007. Available at: http://scholarcommons.usf.edu/etd/2307 . (Retrieved on: 20/2/2015).

20. Erol S, Ertunc M, Ozturk T. The effect of a hand massage on pain and depression in the older people living in a nursing home: pilot study. Journal of Psychiatric Nursing 2014; 5(2): 92-7.

21. American Massage Therapy Association. Massage therapy. 2008. Available at: https://www.amtamassage.org/index.ht ml. (Retrieved on: 25/6/2015).

22. Moyer C, Rounds J, Hannum J. A metaanalysis of massage therapy research. Psychological Bulletin 2004; 130(1): 318.

23. Holland B, Pokorny M. Slow stroke back massage: its effect on patients in a rehabilitation setting. Rehabilitation Nursing 2001; 26(5):182-6.

24. Harris M, Richards K, Grando V. The effects of slow-stroke back massage on minutes of nighttime sleep in persons with dementia and sleep disturbances in the nursing home: A Pilot Study. Journal of Holistic Nursing 2012; 30(4): 255-63.

25. Mok E, Woo C. The effects of slowstroke back massage on anxiety and shoulder pain in elderly stroke patients. Complementary Therapies in Nursing and Midwifery 2004; 10(4): 209-16.

26. Hasankhani H, Ghaderi F, Lakdizaji S, Nahamin M. The effect of the slowstroke back massage on fatigue of dialyzed patients. International Research Journal of Applied and Basic Sciences 2013; 4(10): 3004-8.

27. Bazrafshan M, Ghorbani Z. The Effect of Slow Stroke Back Massages on Anxiety among Primigravid Women. Journal of Hayat 2010; 16(1): 34-40. http://hayat.tums.ac.ir/browse.php?a_co $\mathrm{de}=\mathrm{A}-10-25-95 \&$ slc lang=en\&sid=1 . (Retrieved on: 25/6/2015).

28. Harris M, Richards K. The physiological and psychological effects of slow-stroke back massage and hand massage on relaxation in older people. Journal of Clinical Nursing 2010; 19 (78):917-26.

29. Folstein M, Folstein S, McHugh P. "Mini-Mental State" a practical method for grading the cognitive state of patients for the clinician. Journal of Psychiatric Research 1975; 12(3): 18998.

30. Foreman M, Fletcher K, Mion L, Simon L. Assessing cognitive function: The complexities of assessment of an individual's cognitive status are important in making an accurate and comprehensive evaluation. Geriatric Nursing 1996; 17(5): 228-32.

31. Nilsson F. Mini Mental State Examination (MMSE) - probably one of the most cited papers in health science. Acta Psychiatrica Scandinavica 2007; 116(2): 156-7. 
32. Elhusseini S. Factors related to self-care capabilities among institutionalized elders. Unpublished Master Thesis. Faculty of Nursing, Alexandria University, 2008.

33. Sheikh J, Yesavage J. Geriatric Depression Scale (GDS): recent evidence and development of a shorter version. Clinical Gerontologist 1986; 5(1/2): 165-173.

34. Yesavage J, Brink T, Rose T, Lum O, Huang V, Adey M, Leirer V. Development and validation of a geriatric depression screening scale: A preliminary report. Journal of Psychiatric Research 1983; 17(1): 3749.

35. Elhusseini S. The effect of self-care interventions on quality of life of older adults with heart failure. Unpublished Doctorate Thesis. Faculty of Nursing, Alexandria University, 2013.

36. Beck A, Epstein N, Brown G, Steer R. An inventory for measuring clinical anxiety: Psychometric properties. Journal of Consulting and Clinical Psychology 1988; 56(6): 893-897.

37. Laila S. Impact of applying foot massage on physiological and, psychological status among critically ill patients. Unpublished Doctorate Thesis. Faculty of Nursing, Alexandria University, 2012.

38. Campbell Burton C, Murray J, Holmes J, Astin F, Greenwood D, Knapp P. Frequency of anxiety after stroke: a systematic review and meta-analysis of observational studies. International Journal of Stroke 2013; 8(7): 545-59.

39. Boulanger K, Campo S. Are personal characteristics of massage therapists associated with their clinical, educational, and interpersonal behaviors?. International Journal of Therapeutic Massage and Bodywork 2013; 6(3): 25-34.

40. Smith M. Management of hemiplegic shoulder pain following stroke. Nursing standard: official newspaper of the Royal College of Nursing 2012; 26(44): $35-44$.

41. Atashi V, Mohammadi F, Dalvandi A, Abdollahi I, Kazemi R. Effect of slow stroke back massage (SSBM) on shoulder pain and hand function in patients with stroke. Hayat Journal of Faculty of Nursing \& Midwifery 2012; 18(2): 47-56.

42. Paul N, Das S, Hazra A, Ghosal M, Ray B, Banerjee T, Chaudhuri A, Sanyal D, Basu A, Das S. Depression among stroke survivors: a community-based, prospective study from Kolkata, India. American Journal of Geriatric Psychiatry 2013; 21(9): 821-31.

43. Giaquinto S, Buzzelli S, Di Francesco L, Lottarini A, Montenero P, Tonin P, Nolfe G. On the prognosis of outcome after stroke. Acta Neurologica Scandinavica 1999; 100(3): 202-8.

44. Pettersen R, Dahl T, Wyller T. Prediction of long-term functional outcome after stroke rehabilitation. Clinical Rehabilitation 2002; 16(2): 149-159.

45. Edwardson M, Dromerick A. Ischemic stroke prognosis in adults. 2015. Available at: http://www.uptodate.com/contents/ische mic-stroke-prognosis-inadults?topicKey=NEURO\%2F14086\&e lapsedTimeMs $=6 \&$ view $=$ print $\&$ display edView=full. (Retrieved on: 25/6/2015). 
Slow Stroke Back Massage on Post-Stroke Depression and Anxiety 